\title{
Maternal and New-Born Care Practices by Traditional Delivery Care Givers: A Cross Sectional Survey
}

\author{
Leena Sankar J L ${ }^{1}$, M Amudha ${ }^{2}$ \\ ${ }^{1}$ Lecturer, Sree Gokulam Nursing College, Trivandrum, Kerala, India \\ ${ }^{2}$ Professor and Head of the department, Community Health Nursing, Sree Gokulam Nursing College, Trivandrum, Kerala, India
}

\begin{abstract}
India is a country of great diversity with 29 states and 6 union territories, all varying in language, culture and social traditions. Tradition is defined as belief, custom or way of doing things, that has existed over a long time among a particular group of people. Maternal and child health is influenced by many customs and beliefs. In India marriage is universal and family is incomplete without a child.Various community data obtained support a strong influence of various cultural practices on mortality and morbidity of the mother and new-born. Aim: 1) To identify the practices of maternal care and new-born care by traditional delivery care givers. 2) To determine the association between maternal and new-born care practices and selected socio-personal variables. 3) To identify the harmful maternal and new-born care practices by traditional delivery care givers and provide remedial teaching to modify them. Material and Methods: A descriptive exploratory study was conducted among 200 traditional delivery care givers, selected by convenient sampling from authorised home nursing agencies in Thiruvananthapuram City Corporation, using a semi structured interview schedule prepared by the researcher. Findings: Majority of subjects (65\%) are following beneficial maternal and new-born care practices and 35\% are following harmful ones. Conclusion: More than half of traditional delivery care givers followed beneficial maternal and newborn ocare practices. Remedial teachings after identification of practices were given and correct practices reinforced with rationale. The study recommends periodic review of these practices and a cadre of properly trained personnel to take care of mother and baby at home
\end{abstract}

Keywords: Maternal care Practices, New-born care practices, Delivery care giver.

\section{Introduction}

Mother is the name of God in the lips and heart of children. A mother is a woman who has raiseda child\& given birth to a child. Love of mother is eternal and irreplaceable. Nothing in the world can substitute mothers love. A new-born upon its entry into the air breathing world without the nutrition and oxygen from the umbilical cord, must began to adjust to the life outside the uterus, and the new-born need the assistance of the mother to handle the task with ease. The present study explores the traditional maternal and new-born care practices in Thiruvananthapuram City Corporation.

Child birth is a time of transition and social celebration in many societies, which needs an adjustment of cultural responsibilities. Women's progression from birth to death is influenced by economy, religion, kinship system and growing sophistication of communication and technology. In every country mothers and children constitute a major portion of the total population. Birth of the baby is a cherished dream of the mother and brings joy to the whole family.

India is a country of diversity and wide range of cultural practices in all regions. Various community data obtained support a strong influence of various cultural practices on mortality and morbidity of the mother and new-born. Under the influence of elderly ladies of the families and traditional delivery care givers, even the educated and urban elites follow traditional maternal and newborn care practices. These cultural practices can be classified as good, unimportant, uncertain and bad. ${ }^{1}$
Beneficial practices include prolonged breast feeding, oil bath, massaging and exposure to sunlight. Harmful practices include boring the ear and nose, application of oil and turmeric over the anterior fontennelle etc. uncertain practices include application of kajal over the eyelids and bad practices include eggs, meat, fish, milk and leafy vegetables. ${ }^{2}$

In Kerala traditional practices of postpartum and newborn care aim to restore the balance in the body elements i.e. soil, water, wind and fire. These practices aim at restoring the normal function of sex and reproductive organs, increasing wellbeing and energy of the mothers, encouraging wound healing, weight loss and aesthetic reasons. Giving birth is a period that is described as ,cold ${ }^{\text {ee }}$ hence proper care is given to balance this. These postpartum care practices are practiced throughout the whole confinement period. ${ }^{3}$

Kerala being the highest literate state of India showed a marked difference in infant and maternal mortality rate. The maternal mortality rate is 81 and the infant mortality rate is 12 in 2011 census. This is much less when compared to India, but there are some harmful practices, which is still prevailing in the rural and tribal areas, contributing to this rates. $^{4}$

During the community postings, researcher observed many traditional practices in care of mothers and newborn. All traditional practices are not bad and we must look down on them. Efforts should be made to encourage good one and discard or improve the bad ones. So the researcher planned the study. 


\section{International Journal of Science and Research (IJSR) \\ ISSN (Online): 2319-7064}

Index Copernicus Value (2013): 6.14 | Impact Factor (2014): 5.611

\section{Review of Literature}

In the earliest Indian literature, the Vedas mention that milk and breast are symbolic of longevity and nectarine sweetness. The breast has been conceived as a pitcher full of nectar (Atharva Veda). The Yajurveda (verse 17/87) reflects: "Drink in the middle of the flood, O Agni, this breast stored full of sap, teeming with water. Welcome this fountain redolent of sweetness. O courser, enter those watery dwelling." The CharakSamhita (verses 8/52:957, 8/46:950) depicts the importance of breastfeeding, and the KashyapSamhita describes the qualities of breast milk. Breast milk has been thought to have great powers. Its lifegiving powers are highlighted in select quotations from the religious texts. ${ }^{5}$

An anthropological study was conducted on delivery and new born care practice in urban slumps of Gandha community among 160 mothers using semi structured interview schedule. The study aimed at Knowledge and practice related to delivery and new born care. The study concluded that more than half of mothers (61.87\%) of mothers initiated breast feeding within 2 hours after birth,28.1\%initiated breast feeding within 2-24 hours and only $10 \%$ mothers delayed breast feeding beyond 3 days. $82.05 \%$ of mothers given colostrums to newborns as a first feed, $17.5 \%$ did not give it, because they thought it is harmful for the baby, remaining $8.75 \%$ and $15 \%$ mothers were given honey and cow milk as first feed to the child. ${ }^{9}$

\section{Materials and Methods}

\subsection{Research Approach: Quantitative Research Approach}

3.2 Research Design: Non Experimental Descriptive Exploratory Research Design

3.3 Setting of the study: The study was conducted on selected authorised home nursing agencies in Thiruvananthapuram City Corporation.

3.4 Population: All traditional delivery care givers in Thiruvananthapuram district.

3.5 Sample: All traditional delivery care givers in selected authorised home nursing agencies in Thiruvananthapuram City corporation.

3.6 Sample size: 200 Traditional delivery care givers from Thiruvananthapuram City Corporation which is calculated using the formula $4 \mathrm{pq} / \mathrm{d}^{2}$ with the percentage of harmful practice as $35 \%$, calculated from pilot study.

3.7 Sample Technique: Purposive sampling

\subsection{Inclusion criteria:}

Traditional delivery care givers,

- Registered non licensed traditional delivery care givers

- Regularly practicing traditional maternal and newborn care

- Available during the time of data collection

\subsection{Exclusion Citeria}

Traditional delivery care givers,

- Who are certified

- Who have undergone any training programme

- Having hearing impairment

- Who are not willing to participate in the study

\subsection{Data Collection Tool}

The tool consists of

- Socio Demographic Performa

- Semi structured Interview schedule for assessing maternal and newborn care practices by traditional delivery care givers

\subsection{Data Collection Procedures}

After getting approval from institutional research committee and institutional ethical committee of SreeGokulam Medical college and research foundation data collection was started. Data collection period started from 7-2-13 to 7-3-13.All authorized agencies were visited and permission obtained for collecting the data. Subjects were selected as per inclusion criteria. Appointment fixed with subjects on succeeding days.Informed consent from subjects obtained after explaining the purpose of the study, before data collection. Data was collected using semi structured interview schedule.

\section{Results}

\section{Maternal Dietary practices}

$40 \%$ of subjects cited that they recommend protein rich food for the postnatal mother, $51 \%$ recommends carbohydrate rich food remaining $9 \%$ recommends fat rich food for the postnatal mothers. $45 \%$ restricts tubers, 20\% large bony fishes and $25 \%$ eggs for the postnatal mothers and red meats $19 \%$.

$28 \%$ of subjects cited that they recommend rice meal four times a day for the postnatal mother, $20 \%$ recommends normal diet, $19 \%$ recommends small and frequent diet and $16 \%$ recommends heavy meals three times a day.

$93 \%$ of subjects cited small fishes for increasing milk production. $6 \%$ of subjects cited that they recommend amaranth and $1 \%$ of subjects recommend milk for increasing milk production for post natal mothers.

$83.3 \% \%$ of subjects restricts fluid for the postnatal mother when compared to $17 \%$ of subjects.

\section{Maternal Bathing practices}

- $35.7 \%$ of subjects recommend bathing on fifth day after delivery, $28.6 \%$ recommends bathing on second day, $26.2 \%$ on third day, $5.7 \%$ on fourth day and only $3.8 \%$ of subjects recommend bathing on first day of delivery.

- $57.6 \%$ of subjects recommend mothers to bathe once daily, $16.4 \%$ recommends bathing on alternate days, and only $10 \%$ of subjects recommend bathing twice daily. 


\section{International Journal of Science and Research (IJSR) \\ ISSN (Online): 2319-7064 \\ Index Copernicus Value (2013): 6.14 | Impact Factor (2014): 5.611}

- $90 \%$ of subjects recommend oil massaging, application of turmeric and hot formentation (vethu) as preparations before bathing, $5.8 \%$ recommends only oil massaging, $3.8 \%$ recommends only hot formentation and $1 \%$ recommends only application of turmeric.

- $60.8 \%$ of subjects recommend luke warm water for bathing postnatal mothers, $15.6 \%$ of subjects recommend tap water and $7.6 \%$ recommends mixture of warm and cold water for bathing postnatal mothers.

- Majority (93.8\%) of subjects recommends adding medicinal herbs to water used for bathing the postnatal mothers and $6.2 \%$ not.

- A quarter (78\%) of subjects recommends use of soap for bathing postnatal mothers when compared to $22 \%$ not.

- $79 \%$ of subjects restricts feeding immediately after bathing while $21 \%$ not.

\section{Maternal Activity, rest and sleep}

- More than half (55.6\%) of subjects recommends rest for 3 months after delivery, $20 \%$ for 28 days, $6 \%$ for 56 Days and $2.4 \%$ recommends rest for only 40 days after delivery.

- Most of subjects (93.3\%) recommend supine position with legs straight for lying and $6.7 \%$ recommends side lying position for taking rest.

- Majority of subjects recommends sexual activity only from 3 months after delivery.

- More than half $(66 \%)$ of subjects cited that they never recommends postnatal exercise while $34 \%$ does.

- $42.4 \%$ of subjects recommends sleeping for 10 hours, $30.8 \%$ for 8 hours, $7.2 \%$ recommends sleeping for 6 hours and only $3.6 \%$ of subjects recommends sleeping for 12 hours after delivery .

- A quarter of subjects $(75.7 \%)$ restricts combing hair during the immediate post natal period (for $1 \mathrm{month}$ ) and $24.3 \%$ not.

\section{Newborn Bathing Practices}

- More than half of the subjects recommend bathing newborn on second day of birth, $24.8 \%$ on fifth day, $9.5 \%$ after cord falls (7-12 days) and $6.2 \%$ on the day of birth.

- Majority (92.4\%) of subjects recommends luke warm water for bathing newborn and $2.4 \%$ of subjects recommend tap water, water warmed on sunlight and mixed water respectively.

- Half (51\%) of subjects recommend morning head bath and evening body bath for the newborn, $38.5 \%$ recommends bathing two times daily, $8.4 \%$ recommends bathing bathing once and only one recommends bathing on alternate days.

- More than half (58.1\%) of subjects recommend bathing for 10 minutes, $27.1 \%$ for 5 minutes, $12.9 \%$ for 15 minutes and only $1.9 \%$ recommends bathing for 20 minutes(knee bath).

- Majority of subjects(74\%) recommend oil massaging, application of trurmeric, and passive exercises for the newborn before bathing the newborn, $14.8 \%$ recommends only oil massaging, $8.1 \%$ only application of turmeric and $3.3 \%$ only passive exercises.

- Majority of subjects(69\%) recommends coconut oil for massaging the newborn, $17.6 \%$ uses others such as branded oils, 9.5\% olive oil and 3.8\% vergin coconut oil for massaging the newborn.

- $40.5 \%$ of subjects recommends special care for newborn eyes during bathing rest not.

- More than half of subjects(55.2\%) recommends use of soap and water for washing umbilical cord, $16 \%$ recommends use of salted oil, $15.7 \%$ recommend use of ointment and $10 \%$ recommends others such as powder, kajal, herbal medicines etc.

- Majority of subjects recommends application of oil over anterior fontennelle when compared to $28 \%$ who does not.

- Majority of subjects(79\%)recommends wiping head with soft clothes, $15 \%$ blows air over anterior fontennelle and $2 \%$ dries hair by vigorously shaking.

- Most of the subjects (80.8\%) massage breast buds during bathing when compared to $32 \%$ who does not.

- Majority of subjects $(92 \%)$ blows air into the newborn ears when compared to $8 \%$ who does not.

\section{Newborn Feeding practices}

- Most of the subjects(62\%) recommend prelacteal feeds for their newborn when compared to $38 \%$ who does not.

- $48 \%$ of subjects recommend on demand feeding for newborn, $47 \%$ recommends feeding every 2 hourly,24\% every 4 hourly and $4 \%$ at other times such as after defecation and toileting, before going for bath and drinks etc.

- Majority of subjects recommends complementary feeds for their newborn before 6 months and $40 \%$ not.

- Majority of the subjects (73.8\%) recommends supine position after feeding newborn, $18 \%$ prone position, $2.9 \%$ side lying.

- Majority of subjects (98) recommends burping newborn after feeding while $2 \%$ never.

\section{New-born general practices}

- Most of the subjects recommend application of kajal over newborn eyes when compared to $19 \%$ who never.

- Majority of subjects advocate use of cradle for the newborn and $10 \%$ does not.

- $74 \%$ of the subjects recommend hanging toys on the cradle while $26 \%$ does not.

\section{Standard of practice}

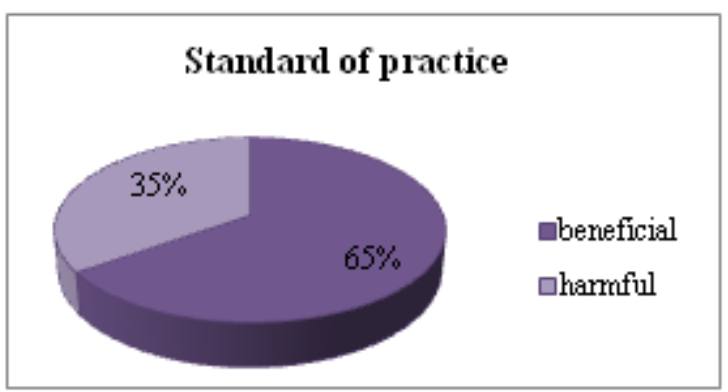

Majority $(65 \%)$ of the subjects are following beneficial maternal and new-born care practices when compared to $35 \%$ who follows harmful practices. There was significant association between standard of practice and selected sociopersonal variables such as religion and year of experience.

\section{Volume 4 Issue 11, November 2015}




\section{International Journal of Science and Research (IJSR) \\ ISSN (Online): 2319-7064}

Index Copernicus Value (2013): 6.14 | Impact Factor (2014): 5.611

\section{Discussion}

The present study showed that half of the subjects $(51 \%)$ recommend carbohydrate rich food for the postnatal mother which is consistent with the study findings by Le Minh Thietal but less than half ( $40 \%$ ) of the subjects recommend protein rich food, which is considered beneficial during immediate postnatal period, which helps in regeneration of body tissues and increases milk production. ${ }^{33}$ The present study showed that majority of subjects $(83.3 \%)$ restricts fluid for the postnatal mothers which is consistent with the study findings by Ayaz.S who conclude that fluid restriction is strictly followed among Turkish women to reduce abdominal distension and bleeding. ${ }^{10}$

Majority of subjects recommend addition of medicinal herbs to water used for bathing the post natal mother, which is explained in detail on Ayuveda text book CharakaSamhitha, as it helps in rejuvenating damaged body tissues and regain lost strength. ${ }^{7}$ In the present study majority of subjects recommends sexual activity only after 3 months of delivery which is consistent with the study findings in another study which stated that post natal sexual activity is safe after 3 months and helps to reduce post natal complication such as wound dehiscence, sub involution and earlier pregnancy. ${ }^{2}$

The present study showed that majority of subjects (92.4\%) recommended luke warm water for bathing newborn which is consistent with the study finding by another study, which recommends luke warm water for preventing hypothermia and restrict use of cold water for bathing newborn. ${ }^{8}$

\section{Future Scope}

- Student nurses and nurse educators can be informed about research result, so that they can promote them.

- Research result adds to the body of knowledge of nursing education.

- The research finding can be included in nursing curriculum so as to improve patient care.

- The research pays a way for nurse education and student nurses to explore Kerala tradition regarding care of mother and newborn.

- Remedial and corrective teaching regarding harmful traditional practice can be done by student nurses with the motivation of nurse educators.

\section{Nursing Practice}

- Research findings can be used to modify patient teaching.

- Various components of beneficial traditional maternal and newborn care practices can be included in the immediate patient care.

- Training of registered traditional delivery care givers on maternal and newborn care practices can be organized.

\section{Nursing Administration}

1) Nurse administrator can pay special attention in including beneficial traditional maternal and newborn care practices in modern medicine.
2) Orientation and training program for staff regarding traditional practices can be organized.

\section{Nursing Research}

- The research results add to the body of knowledge of nursing research.

- Further studies can be conducted to explore more traditional maternal and new-born care practices with larger sample.

\section{Community}

- Research findings can be informed to the public to create awareness.

- Corrective teaching to the public whenever harmful practices are detected.

- Beneficial traditional practices could be demonstrated to the public.

- Awareness program regarding various practices can be conducted.

- Local traditional delivery care givers can be identified and practices assessed using the research data.

\section{Limitations of the study}

Generalisation was limited due to small sample size and convenient sampling technique.Practice in real life situation could not be assessed as it used semi structured interview schedule. Observation method of data collection was much better for the study.The effect of remedial teaching given was not assessed.Practices of registered traditional delivery care givers were only assessed during the time of data collection, but there were many unregistered traditional delivery care givers providing traditional maternal and newborn care practices, not included in the study.

\section{References}

[1] SudhaNambudiri.Raring to give Baby the best.TheHindhu [Internet] .2002 jun 24 [cited 8 Jun 2013]: [About 1p].Available from : $\mathrm{http} / / \mathrm{www}$. thehindu.com

[2] Suresh Patel.Indianethinicity and background.india:Availablefrom:http://www.health.qidg ov.aa/multicultural.

[3] Andrew R.The importance of postpartum care.baby centre [internet].2010 Jan [cited 2012 May];2(3):[about $3 \mathrm{p}]$.Available from: http://www.thenewage parents.com.

[4] Kulkarni M L.An atlas of Neonatology. $1^{\text {st }}$ ed. Newdelhi: Jaypeebrother"spublication; 2005.

[5] YoaZ.Sexual problems of postnatal mothers.Pubmed[internet]2000 Jan[cited 2012 may 5];95(1):[about 4p].avilable from :http://www.ncbi.nlm.nih.gov/pubmedring.

[6] Leigh S,SarahJ,Bronwyn S etalComparingsleep duration and quality prior to and during late pregnancy[internet]2012 jan[cited 2012 April 29];10(1):[about from:http://www.mumsleep.co.nz.

[7] Jennifer A. raising natural kids.[internet].2012april [cited 2012 may].Available from http://www.raisingnaturalkids.com. 


\section{International Journal of Science and Research (IJSR) \\ ISSN (Online): 2319-7064}

Index Copernicus Value (2013): 6.14 | Impact Factor (2014): 5.611

[8] Fiona S.Advice for bathing your newborn.2013 March.Availablefrom.http://au.lifestyle.yahoo.com.

[9] PromilaK,Yadav J, Kumar S etal.Folk medicine used in gynaecological and other related problems.Indian journal ot Traditional medicine. [internet]. 2006 July [cited 2012 Jan 18]; 5(3): [about 3p]. Available from : http.//www.iniscairires.in.

\section{Author Profile}

Mrs.LeenaSankar J L MSc (N) did her Bachelors degree in Nursing from CSI College of Nursing, Karakkonam. She received her Masteres in Nursing from SreeGokulam Nursing College, Trivandrum. Currently she is working as Lecturer in Community Health Nursing Dept., SreeGokulam Nursing College, Trivandrum.

Mrs. M Amudha MSc (N) did her Bachelors and Masters in Nursing from Vinayaka Mission AnnapoornaCollege of Nursing, Selam, Tamilnadu. Currently she is working as Professor and HOD, Community Health Nursing, SreeGokulam Nursing College, Trivandrum. 